\title{
Psychiatric Disorders of Face Recognition
}

\author{
Chloé Wallach and Sadeq Haouzir \\ Centre Hospitalier du Rouvray \\ France
}

\section{Introduction}

Reports of cases of patients suffering from an impairment of the brain function of face recognition have appeared in the medical literature since 1923. In some instances the cause is a cerebral accident, others occur in the context of a psychiatric condition.

Those face recognition disorders associated with psychiatric diseases are called misidentification syndromes and may be less well known by clinicians.

There are several syndromes, all defined by the delusional belief that familiar people or even the patient himself have been replaced by doubles or sosies.

The first and most common disorder to have been described is the Capgras delusion named after French Professor Jean-Marie Joseph Capgras who, with his intern Jean ReboulLachaux, first described this "curious little syndrome"1 as he named it (Capgras \& ReboulLachaux, 1923).

\subsection{Clinical interest of Capgras delusion}

Clinical studies of this pathology are justified and valuable because it is a disease that is stable over time, that can last for years and that is similar between patients whatever the context.

Hence Capgras delusion seems to be a basic concept, a clinical entity that is found in several diseases, both of lesional (neurologic, iatrogenic, infectious...) or psychiatric etiology. This observation has given rise to numerous debates about whether Capgras delusion is a symptom or a syndrome, a controversy that we won't discuss in this chapter.

\subsection{Psychopathological interest}

Understanding the abnormality in Capgras delusion could help understand the physiology underlying the identification and recognition of individuals by the human brain.

In this chapter, we first clinically describe the Capgras delusion and other misidentification syndromes in their historic version. Then we examine the different explanatory models that have been reported in the scientific literature, considering psychodynamical hypotheses, neurocognitive and neuro-lesional theories and finally global models.

\footnotetext{
${ }^{1}$ In French "un curieux petit syndrome"
} 


\section{Clinical description of misidentification syndromes}

\subsection{Some epidemiological data}

Several classifications of psychiatric diseases have been developed because psychiatry is mainly a clinical science. As Capgras delusion occurs in many diseases, no standard definition exists for this particular entity in the current international classifications such as in the Diagnostic and Statistical manual of Mental disorders (APA, 1994) or the International Classification of diseases (WHO, 2010).

Thus evaluating its frequency is challenging. Capgras delusion is believed to occur seldom (or stays unnoticed), but seems to be the most common of the misidentification syndromes known.

Its prevalence varies widely across studies. Huang et al. report a prevalence of $2.5 \%$ among patients admitted in the psychiatric unit of the Memorial Hospital of Chang Gung in Taiwan between October 1994 and November 1995 (Huang et al., 1999, as cited in Henriet et al., 2008) against $0.14 \%$ for Fischbain among patients admitted to the psychiatric emergency unit of the Jackson Memorial Hospital in Miami during the year 1983 (Fishbain, 1987, as cited in Henriet et al., 2008).

\subsection{Historical description of Capgras delusion}

French Professor Jean-Marie Joseph Capgras and his intern Jean Reboul-Lachaux presented the original case of Mrs M. to the Clinical Society of Mental Health in Paris in 1923. He first termed it "l'illusion des sosies" (Capgras \& Reboul-Lachaux, 1923).

Mrs M., a 53 year old seamstress, was living in Paris with her husband and their 20 year old daughter. She was hospitalized in 1919 in the French psychiatric hospital Maison-Blanche after asking the Police to help her free the many people sequestrated in the basement of her house and throughout Paris. Professor Capgras reported how Mrs M. explained that she was the victim of a vast conspiracy of "sosies", real people being imprisoned underground while their doubles act badly.

"Her husband [...] also disappeared: a sosie took his place; she wanted to divorce this sosie; she drew up a complaint and requested a separation from the court. Her real husband was murdered and the "gentlemen" who come to visit her at the hospital are "sosies" of her husband; she counted at least eighty of them. [...] "If this person is my husband, she says, he is totally unrecognizable, he is transformed. I certify that this so-called husband that they are trying to foist on me in fact ceased to exist ten years ago"." 2

"To replace my stolen daughter, they always put another one who was in turn removed and immediately replaced ... Whenever they took away a child, they gave me another one who looked like her. I had over two thousand in five years [...]. Every day girls came to my home and every day they were taken away; I warned the Police Superintendent, saying that their parents had disappeared and that these girls had pricks to the face to remove all their ideas

\footnotetext{
${ }^{2}$ In French "Son mari [...] a également disparu : un sosie a pris sa place ; elle a voulu divorcer d'avec ce sosie ; elle a adressé une plainte et fait une demande de séparation au Palais. Son véritable mari a été assassiné et "les messieurs" qui viennent la voir sont des "sosies" de son mari ; elle en a compté au moins quatre-vingts. [...] Si cette personne est mon mari, il est plus que méconnaissable, c'est une personne métamorphosée. Je certifie que le prétendant mari que l'on cherche à m'insinuer pour le mien n'existe plus depuis dix ans."
} 
and that they were abused ... This coming and going of children at my house lasted from 1914 to 1918 without interruption."3

"But disappearances go well beyond the family of Mrs. M., extending to her household, to the whole world and especially to Paris. [...] All the people who are around Mrs M. every day at the hospital have their sosies. [...] The head of department has been replaced by sosies and when asked if she is certain, she stops and then, with conviction, exclaims "The doctors who come here with a cloak, you can't tell me there is only one: I know at least fifteen of them! "' 4

The patient herself uses the word "sosie". The concept of the existence of doubles is the clinical particularity of this delusion for Capgras.

Capgrass and Reboul-Lachaux explained the process of face recognition as a struggle between two feelings caused by the visual stimulus: a sense of familiarity and a sense of strangeness, which he compared with the mixed feelings one has when confronted with someone one hasn't seen in a long time.

In the case of Mrs. M., the sensory recognition is associated with the feeling of strangeness, the sense of familiarity has disappeared. Capgras believed it didn't come from a sensory disorder but from a primary affective disorder with a secondary delusional interpretation or, as Capgras said "an emotional state first, then a habit, finally an automatic state of mind." 5

\subsection{Other misidentification syndromes are known \\ 2.3.1 Fregoli delusion}

The "syndrome d'illusion de Frégoli" was first described in 1927 by two French psychiatrists, Paul Courbon and Gustave Fail (Courbon \& Fail, 1927, as cited in Henriet et al., 2008).

In this syndrome, the patient holds the delusion that different people who have no physical resemblance are in fact a single person who changes appearance or is in disguise, like the famous Italian actor Leopoldo Fregoli (1867-1936) who was renowned for his ability to make quick changes of appearance during his stage act.

In the original case, a 27 year old French woman, a servant, believed she was the victim of two actresses, Sarah Bernhardt and Robine, who had the capacity to take over the bodies of the people she met, to take her thoughts or to make her do specific acts. Her persecutors had

\footnotetext{
3 "Pour me remplacer ma propre fille volée, on en mettait toujours une, à son tour enlevée et remplacée aussitôt... Au fur et à mesure qu'ils m'enlevaient une enfant, ils m'en donnaient une autre qui lui ressemblait. J'en ai eu plus de deux mille en cinq ans [...] Il venait journellement des fillettes chez moi qui journellement m'étaient enlevées ; j'ai prévenu le Commissaire de police du quartier Necker lui disant que leurs parents avaient disparu et que ces fillettes avaient des piqûres à la physionomie pour leur enlever toute idée et qu'elles étaient maltraitées... Ce va-et-vient d'enfants chez moi a duré de 1914 à 1918, sans discontinuer."

4 "Mais les disparitions débordent largement le milieu familial de Mme M., pour s'étendre à sa maison, au monde entier et spécialement à Paris. [...] Tous les gens qui entourent journellement Mme M. à l'asile ont leurs sosies. [...] On a remplacé le chef de service par des sosies et comme on lui demande si elle en est bien certaine, elle s'arrête, puis, avec conviction, s'exclame "Les docteurs qui viennent ici avec les pèlerines, vous ne me direz pas qu'il n'y en a qu'un : j'en connais au moins quinze ! " "

${ }^{5}$ In French "un état affectif d'abord, une habitude, une tournure d'esprit ensuite"
} 
the power of Fregoli and could even "fregolify" other people, meaning to put other people than themselves inside the bodies of relatives of the patient.

\subsubsection{Intermetamorphosis or "syndrome d'intermétamorphose et de charme"}

Soon after Capgras delusion and Fregoli syndrome, a case of "intermetamorphosis" was presented to the medical and psychological society meeting in Paris by Paul Courbon and Jean Tusques (Courbon \& Tusques, 1932).

The main symptom is the belief that the body and soul of different people are incarnated in the body of a single person.

\subsubsection{The syndrome of subjective doubles}

In this more recently described pathology (Christodoulou, 1978, as cited in Henriet et al., 2008), the subject experiences the illusion that he or she has one or more doubles with the same physical appearance but different character traits, with each double leading a life of its own.

\subsection{What misidentification syndromes have in common (Weinstein, 1994, as cited in Henriet, 2003)}

A first common trait is the belief in duplication of people. Each patient suffering from one of these syndromes has the idea that multiple versions of people can exist at the same moment (but not at the same place).

This illusion of substitution comes from an agnosia of identification: the impersonator is physically identical (i.e. physically recognized) but psychologically different (the sense of familiarity that should accompany the visual recognition has disappeared).

The impersonator uses his resemblance with the real person to persecute the patient; he is always ill intentioned.

The person replaced isn't chosen at random. In most cases the person is emotionally related to the patient, by attraction or repulsion.

Finally, in every case, the fate of the " original » person seems quite unimportant: he or she may have disappeared, been kidnapped, confined, murdered... The explanations are often poor and evasive, given with little emotion.

\subsection{Their differences according to the literature}

To work on these syndromes, authors tried to classify them according to their differences, suggesting that the psychopathology processes could be different.

For Jacques Vié in 1930, all of the misidentification syndromes are a single disease that he calls "syndrome des sosies" and that can take two forms: a positive and a negative form. In the first category, the patient finds imaginary resemblances between people; Vié in this case describes the sosies as "positive", as in Fregoli delusion or intermetamorphosis. In the second category, the person denies the identity of his relative, discovering tiny differences between the "original" person and his sosie, creating a "negative" double. Capgras delusion or the syndrome of subjective doubles are examples of the negative form of syndrome des sosies (Vié, 1930).

Georgios Christodoulou in 1977 proposed the same kind of classification, distinguishing hypo-identification from hyper-identification syndromes (Christodoulou, 1977, as cited in Henriet, 2003). Some specific facial recognition tests could differentiate between these two 
sub-groups of patients suggesting that the facial recognition process is altered in different ways in the two groups (Walther et al., 2010).

Oyebode in 1996 identified patients who recognize familiar faces (Capgras), and patients who recognize unfamiliar faces (Frégoli). According to this author, this distinction could mean that these two syndromes come from two different anatomical lesions, considering that the recognition process for familiar faces would be located in the right temporal lobe whereas for unfamiliar faces the right parietal lobe would be implicated (Oyebode et al., 1996, as cited in Henriet, 2003).

\subsection{These clinical entities are found in several pathologies}

Capgras delusion can be associated with organic diseases like epilepsy, stroke, iatrogenic pathologies or infectious diseases. Capgras delusion seems to be mostly found coupled with psychiatric disorders, mainly paranoid schizophrenia, but also mood or schizoaffective disorders.

A case of isolated Capgras was described by Henriet et al. in 2006. A 59 year old woman believed her husband and daughter were replaced by evil sosies. The paraclinical test results (blood test, electroencephalogram, cerebral scan, single photon emission computed tomography, intellectual efficiency) were normal, showing no neurological disease. The psychiatric exam didn't reveal any schizophrenia, chronic hallucinatory psychosis, paranoid psychosis or mood disorder. She had a similar episode four years earlier and recovered without treatment at the time, keeping her social and professional position.

\subsection{Differential diagnosis}

The "recognitions" in Capgras delusion are different from false recognitions which are defined by the recognition of an unknown person. Patients with false recognitions perceive face similarities when there aren't any whereas patients with Capgras detect tiny details to justify their denial of the identity of the person.

Capgras is not a memory disorder because the patient doesn't have any trouble remembering the faces of the people whose identity he denies.

Capgras differs also from prosopagnosia. The latter is the inability to recognize faces of familiar people by sight (but the person can be recognized by his or her voice, glasses, mustache...), but is not accompanied by the mention of the existence of sosies or by persecutory delusional experiences.

The symptoms of paramnesia of reduplication look like Capgras delusion because the patient holds the delusional belief that a place or a person familiar to him has been duplicated, but there isn't any notion of substitution or imposture.

\section{Explanatory models of face recognition}

Three categories of models have been considered in the scientific literature. Psychodynamic theories inspired by psychoanalysis were initially preferred given the selective nature and the emotional value of the sosified person (most of the time a family member, or the patient's caregiver).

Neuro-lesional models have been developed starting from the 1960s with the objective of locating the face processing area in the human brain, using anatomical and functional neuro-imaging techniques. 
More recently the development of cognitive neuropsychology offered a different approach based on models of the face processing function, trying to discover not the brain structure responsible for the dysfunction, but the cognitive operation deficiency.

\subsection{Psychodynamic models}

These models were mainly developed at the time of the first description in 1923, approximately when Sigmund Freud was elaborating his psychoanalytic theories, in particular in his book "The Uncanny" ("Das Unheimliche") where he discusses the concept of the "double" (Freud, 1919, as cited in Henriet, 2003).

The first theory is the hypothesis of depersonalization where the notion of sosie would be due to the projection by the patient of his own "Uncanny" on others. The patient finds it easier to believe that others have changed rather than himself. Hence the impression of "not being oneself" becomes the impression of others "not being themselves", having been replaced by sosies.

The most widely accepted psychodynamic theory currently is the hypothesis that Capgras delusion is a psychotic solution to the problem of ambivalence.

The definition of ambivalence in psychoanalysis is the fact of having simultaneously contradictory feelings toward a person, usually love and hate. The defense mechanism used to cope with these conflicting feelings depends on personality.

For patients suffering from Capgras delusion, the defense mechanism used to cope with the split between the feeling of hate and the feeling of love would be the idea of the existence of two persons: a bad one, the sosie, considered as an impostor and a persecutor, and a good one, the "original" person. This theory allows the patient to continue loving his or her relative while expressing his or her hate of the sosie without any feeling of guilt.

Capgras delusion is also believed to result from early relational disturbances, or a childhood trauma causing a loss of confidence in the reality of the objective world or even an attempt to overcome a poorly repressed Oedipius complex.

Jean-Marie Joseph Capgras' own etiological hypothesis is a primary affective disorder because of the simultaneous feelings of familiarity and strangeness. He explained that the belief in sosies is the intellectual conclusion of disturbed feelings.

\subsection{Psychometrics}

Neuropsychological tests are based on the concept of the human face as a specific recognition object. Thus the human face is seen as a geometric figure that changes with age, mood, health status, presence of accessories (glasses, make-up ...) or expressed emotions.

Psychometric tests use match-to sample, discrimination or naming of human faces which differ in the viewing angle, the sex, the age, the expressed emotion, the pose, the features... For instance, the Benton Face Recognition Test (Benton \& Van Allen, 1968 as cited in Vanier, 1991) evaluates face identification skills by matching pictures of non familiar faces presenting differences in the lighting or the viewing angle. The Bruyer and Schweich face recognition battery uses a famous faces discrimination task and identification subtests of features independent of the expression (Bruyer \& Schweich, 1991). Familiarity can also be experimentally induced before the tests with repeated exposure to a face.

Neuropsychological models have been developed based on the test errors observed in Capgras delusion and prosopagnosia patients. 


\subsubsection{Bruce and Young's sequential model}

Bruce and Young imagined a three step model of face recognition that progresses in a particular order (Bruce \& Young, 1986, as cited in Ellis, 2004).

The first step is the encoding (i.e the conversion of the stimulus to information that can be stored in memory) of general physical characteristics such as age, sex or skin color and of physiognomic characteristics that are unique to this face.

The next step is the comparison of this information with the memory stock of familiar people (composed of different Face Recognition Units or FRU), producing or not the feeling of familiarity.

If the face is familiar, the final step consists of the stimulation by the FRU of the Person Identity Node (or PIN) containing the relevant semantic and biographical information.

In Capgras delusion, the third step would be disturbed resulting in a dysfunction of the access to the sosified person's PIN, the recognition of his face (steps 1 and 2) being preserved but not his identification. The familiar face activates the information related to the imaginary persecutor and not those of the real person.

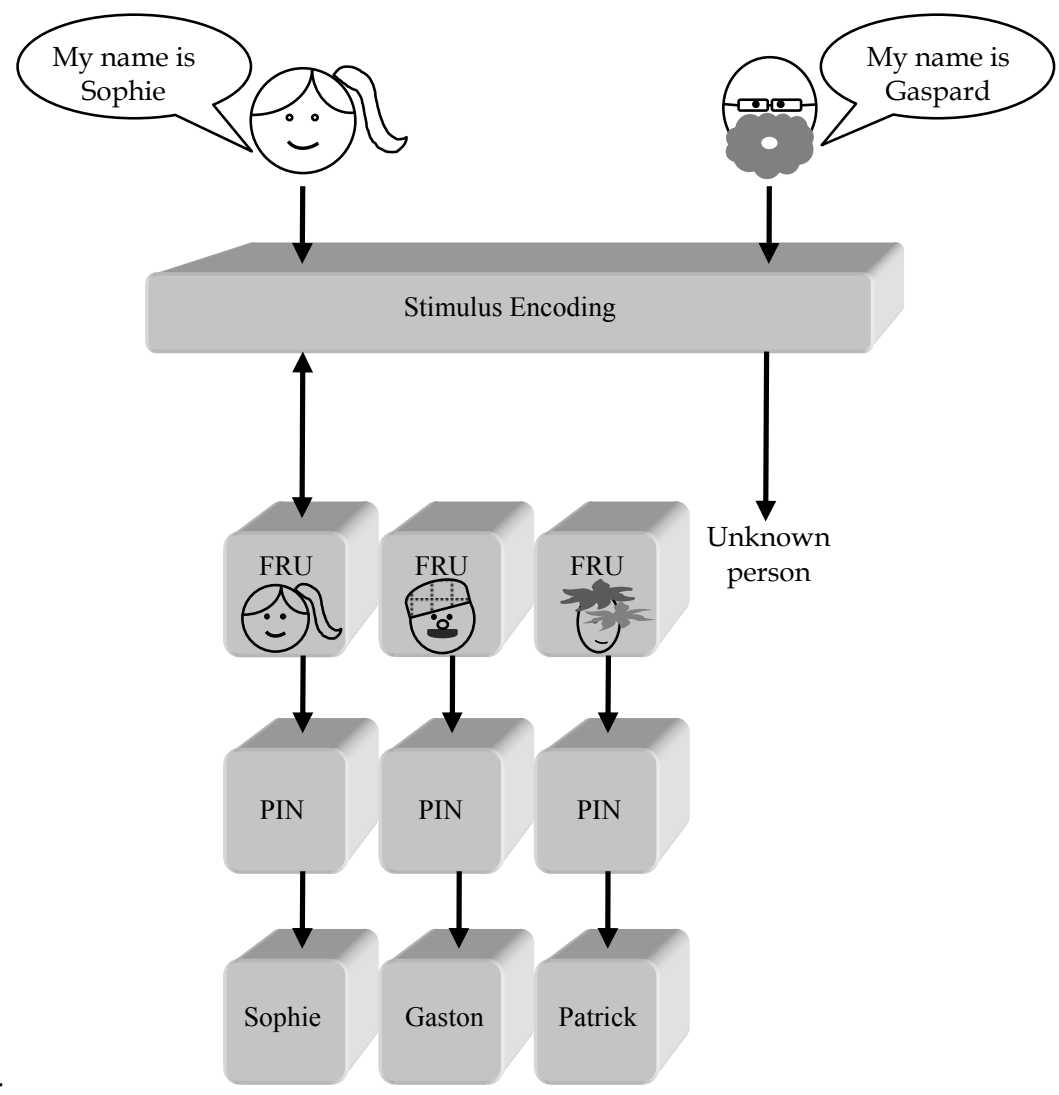

Fig. 1. A simplified version of Bruce \& Young's sequential model. A familiar face activates the corresponding Face Recognition Unit (FRU), then the Personal Identity Node (PIN), finally the Name Retrieval Module (Bruce \& Young, 1986, as cited in Ellis, 2004). 
This sequential model is currently supplanted by a serial model which better accounts for Capgras delusion.

\subsubsection{The two-route model of face recognition has become a widely accepted hypothesis}

Bauer suggested another model, based on the observed emotional reactivity caused by a face in prosopagnosic patients (Bauer, 1984, 1986, as cited in Breen et al., 2000). He assumed that emotional reactivity could be measured by "skin conductance response" (which varies with the skin's sweating level), and that a change in this parameter would represent an unconscious recognition of the face. In prosopagnosia, a change in the patient's skin conductance response appears when he is confronted with a familiar face, but he isn't capable of consciously recognizing his relative. Bauer concluded that there are two parallel pathways, instead of one in the first model, connecting the visual cortex to the limbic system (an association of cerebral areas believed to support emotion, behavior, and memory skills).

The first is an overt ventral route via the inferior temporal lobe which makes it possible to recognize consciously and explicitly the identity of the observed face.

The second is the covert dorsal route going via the superior temporal sulcus and the inferior parietal lobule which is responsible for the affective and unconscious recognition of the face. In a 1990 paper published in the British Journal of Psychiatry, psychologists Ellis and Young, considering Bauer's model, suggested that Capgras delusion could result from a dysfunction of the dorsal route with an intact ventral route (Ellis \& Young, 1990, as cited in Henriet et al., 2008).

In the case of patients with Capgras delusion, the Ellis and Young hypothesis was confirmed with the observation of a deficit in emotional reactivity while the conscious awareness of recognition is preserved (Hirstein \& Ramachandran, 1997). The patient physically recognizes his relative's face but doesn't have the affective confirmation of this recognition. Faced with this conflicting information, he calls upon rationalization and concludes that there must be a sosie of his relative. The authors emphasized the fact that the face recognition deficit in Capgras delusion is selective to the visual domain. Indeed some patients remain capable of recognizing their sosified relative by his voice.

Ellis and Young also hypothesized Capgras delusion could be the "mirror" of prosopagnosia. In Bauer's model, prosopagnosia would represent an interruption in the overt route, whereas Capgras delusion would result from an impairment of the covert pathway.

\subsubsection{Breen's serial model}

Breen et al. proposed in 2000 a bidirectional cognitive model of face processing based on Bauer's model. They state that there isn't any evidence supporting the theory of two anatomical regions responsible for face recognition. Thus they claim that the visual-limbic ventral route described by Bauer is the sole face processing area of the human brain.

They argue that within this area there are two functional pathways from the Face Recognition Unit, one leading to the related Personal Identity Node, the other to an "affective response to familiar stimuli" module. The two pathways are independent.

According to the authors, Capgras delusion would be the outcome of a lesion or a dysfunction in the access to the additional module, whereas prosopagnosia would be the result of a dysfunction in the FRU or in the access to the associated PIN. 


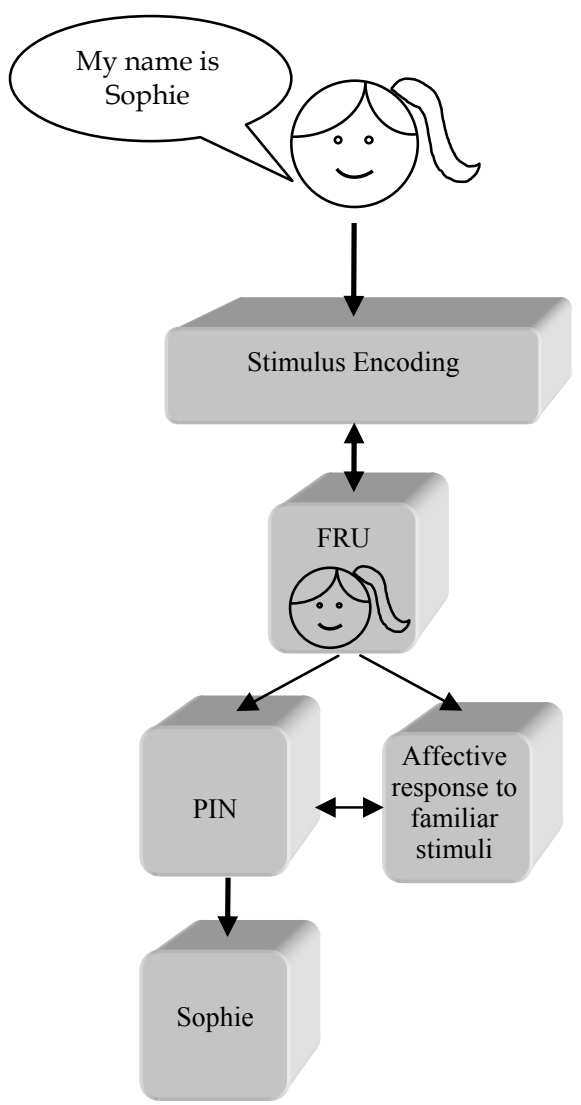

Fig. 2. A simplified version of Breen's serial model based on Bauer's theory. Two independent cognitive pathways leading to the person's identification but one anatomical route (Breen et al., 2000). 


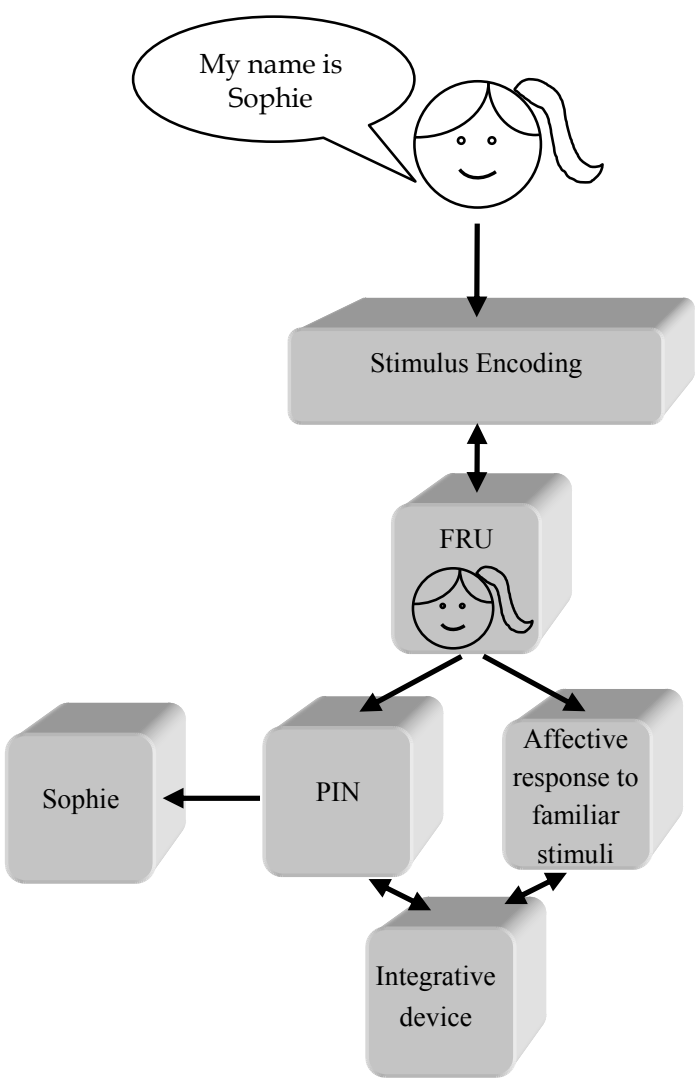

Fig. 3. An adapted version of the Ellis and Lewis model model. The Personal Identity Node (PIN) and the affective response module are connected by an integrative device (Ellis \& Lewis, 2001, as cited in Henriet, 2003). 


\subsubsection{Ellis and Lewis add a step to Breen's model}

They suggest that the information coming from the recognition system and the affective response system are re-integrated to be matched with the memorized face (Ellis \& Lewis, 2001, as cited in Henriet, 2003). This processing would take place in an "integrative device". Capgras delusion would appear if the face is recognized but the familiarity response is not confirmed.

\subsection{Neuro-lesional models}

Neuro-lesional models of Capgras delusion were developed after cases of Capgras delusion associated with organic diseases and not just psychiatric conditions were described, for instance with migraine or cerebral localization of human immunodeficiency virus. New paraclinical tests have also become available, especially neuro-imaging techniques.

Cases of prosopagnosia have been widely studied to understand the anatomical support of face recognition. Results have been extrapolated to account for Capgras delusion.

\subsubsection{A right hemisphere dysfunction}

Ellis in 1994 suggested that Capgras delusion results from a right hemisphere dysfunction based on two arguments (Ellis, 1994, as cited in Henriet, 2003).

The first argument was that schizophrenia is due to a right hemisphere dysfunction (Cutting, 1985, as cited in Henriet, 2003), a hypothesis that is currently widely criticized.

The second argument was based on a literature review (Feinberg \& Shapiro, 1989, as cited in Henriet, 2003) which demonstrated that the majority of patients with Capgras delusion associated with brain abnormalities (they listed 26 patients in this situation in the literature) had bilateral lesions. If lesions were unilateral (the case for 8 among the 26 patients), the lesions were most often in the right hemisphere.

His hypothesis was supported by cognitive neuropsychological data from his 1993 study where he presented two images of faces in the right or the left visual hemi-field to a group of 3 patients with Capgras delusion and to a control group of 3 patients diagnosed with schizophrenia (Ellis et al., 1993, as cited in Henriet et al., 2008). The subjects had to determine whether the two faces were identical or different, and their answer was timed. He postulated that "normal" subjects would react faster when the images are presented in the left side of their visual field, because the right cerebral hemisphere would process the stimulus faster than the left one. The results in the Capgras delusion group showed no difference between the two hemi-fields, whereas the answer was faster in the left hemi-field for the schizophrenia group. Ellis's conclusion, aside from contradicting Cutting's theory about schizophrenia, was that the face processing deficit in Capgras delusion is located in the right hemisphere.

\subsubsection{Gobbini and Haxby incorporate neuro-imaging data within neuropsychological models (Gobbini \& Haxby, 2007)}

Recently, functional magnetic resonance imaging (fMRI) studies have found anatomic regions giving rise to face-related activity in the right hemisphere. An association of two cortical networks, a core and an extended one, are believed to be in charge of the different functions implicated in face recognition.

The core system could be composed of separate anatomical regions, like the lateral portion of the mid-fusiform gyrus or "fusiform face area" or FFA which has been discovered 
bilaterally but predominantly in the right hemisphere (Kanwisher et al., 1997, as cited in Gobbini \& Haxby, 2007). Other occipito-temporal areas are supposed to be part of this network, such as regions in the inferior occipital gyrus (or occipital face area or OFA) or the superior temporal sulcus (or STS) (Haxby et al., 2000, as cited in Gobbini \& Haxby, 2007).

This core face processing network could be further connected to an extended network for which the anatomical substrate has not been yet completely discovered, contrary to the core system.

Using Breen's neuropsychology model, the authors assume that the core system is responsible for the perception stage of face processing and the extended network for the memory operations of facial processing. The PINs are believed to be located in this extended network.

Given the anatomical segregation of these processes, damage can either appear in the specific regions or in their connections, and create various symptoms depending on where they occur. This hypothesis could support the fact that diverse lesions can lead to similar deficits, explaining the multiplicity of lesions found in neurologic Capgras delusion.

\subsection{3 "Right brain lesions and left brain delusions"}

Hirstein \& Ramachandran in 1997, then Devinsky in 2009 postulate that Capgras delusion (and misidentification syndromes in general), when associated with a neurologic disease, is due to frontal lobes and/or right hemisphere dysfunction while specific (but unknown) left brain areas are preserved.

Right hemisphere lesions would be responsible for errors in emotions related to face stimuli and self-monitoring. Left preserved areas then "unleash a creative narrator" from these erroneous data and, since the cognitive method of classification of the left hemisphere is often binary, the patient with Capgras delusion imagines two different people instead of one.

\subsubsection{Conclusion about neuro-lesional models in Capgras delusion}

The paraclinical data are scarce and Capgras delusion rarely diagnosed. The explanatory models are mainly based upon prosopagnosics or neurologic Capgras. Hence it seems difficult at present to formally conclude that an anatomical lesion alone is responsible for Capgras delusion.

In addition, these theories cannot account for cases of Capgras delusion associated with psychiatric diseases where no cerebral abnormality is found, and certainly not for the case of isolated Capgras delusion described above.

The Gobbini and Haxby's model integrates paraclinical observations in neuropsychological models, opening the path to other propositions of global theories for Capgras delusion.

\subsection{Global approach to Capgras delusion}

The model of Capgras delusion based on Bauer's two-route theory seems confirmed by anatomical data and by neuropsychological explanations, supporting global hypotheses for the development of Capgras delusion.

Henriet in 2003 has proposed a global model integrating psychodynamic, organic and functional theories.

The first step in the development of Capgras delusion would be a functional neuropsychological deficit sometimes but not always due to organic lesions. 
The patient would need to have a specific personality with "paranoid" traits and defense mechanisms such as projection or interpretation where this functional deficit would appear. All these phenomena lead to a secondary delusional rationalization, producing the symptoms of Capgras delusion.

\section{Conclusion}

The cleavage between organic and functional etiology is currently outdated and denied. Capgras delusion seems to be a transnosographic entity, which starts as a lesional or functional impairment, and then manifests as a psychiatric disorder.

Research in this area shows that cerebral face recognition processing is complex and not currently fully understood. Face recognition depends on a combination of anatomical structures, cognitive functions and psychopathological processing. Global approaches must be used to explore its dysfunction and function.

It is important to emphasize that, beside its scientific interest this syndrome remains a real source of pain for patients and their caretakers.

\section{References}

American Psychiatric Association (2000). Diagnostic and Statistical Manual of Mental Disorders, Fourth Edition - Text Revision (DSM IV-TR). APA, Washington

Breen, N.; Caine, D. \& Coltheart M. (2000). Models of face recognition and delusional misidentification: a critical review. Cog neuropsychol, 17, 55-71

Bruyer, R. \& Scweich M. (1991). A clinical test battery of face processing. Intern. J. Neuroscience, 61, 19-30

Capgras, J. \& Reboul-Lachaux, J. (1923). L'illusion des “sosies" dans un délire systématisé chronique. Bul Soc Clin Med Ment, 11, 6-16

Courbon, P. \& Tusques, J. (1932). Illusions d'intermétamorphose et de charme. Ann Med Psychol, 90, 401-405

Devinsky, O. (2009). Neurology, 72, 80-87

Gobbini, M.I. \& Haxby, J. (2007). Neural systems for recognition of familiar faces. Neuropsychologia, 45, 32-41

Ellis, H.D. (2004). Cognitive neuropsychology and delusional misidentification of persons. Ann Med Psychol, 162, 50-54

Henriet, K. (2003). L'illusion des sosies de Capgras: syndrome ou symptôme? Revue de la littérature, thèse pour le doctorat en médecine, faculté de Rouen

Henriet, K. ; Haouzir, S. \& Petit, M. (2008). L'illusion des sosies de Capgras: une interprétation délirante d'un trouble spécifique de la reconnaissance des visages. Revue de la littérature et proposition d'un modèle séquentiel. Ann Med Psychol, 166, 147-156

Hirstein, W. \& Ramachandran, V. S. (1997). Capgras syndrome: a novel probe for understanding the neural representation of the identity and familiarity of persons. Proc Soc Lond, 264, 437-444

Luauté, J.P. (2009). Neuropsychiatrie cognitive des délires d'identification des personnes. Une revue historico-critique. L'évolution psychiatrique, 74, 93-121

Vanier, M. (1991). Test de reconnaissance des visages de Benton, 
Vié, J. (1930). Un trouble de l'identification des personnes, l'illusion des sosies. Ann Med Psychol, 88, 214-237

Walther, S.; Federspiel, A.; Horn, H.; Wirth, M.; Bianchi, P.; Strik, W.; Müller, T. (2010). Performance during Face Processing Differentiates Schizophrenia Patients with Delusional Misidentifications. Psychopathology, 43, 127-136

World Health Organization (2010). International Classification of Diseases, Tenth Revision, Clinical Modification (ICD-10-CM). WHO, Geneva 


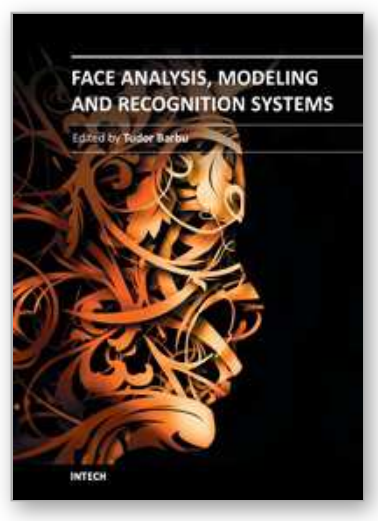

\author{
Face Analysis, Modeling and Recognition Systems \\ Edited by Dr. Tudor Barbu
}

ISBN 978-953-307-738-3

Hard cover, 212 pages

Publisher InTech

Published online 30, September, 2011

Published in print edition September, 2011

The purpose of this book, entitled Face Analysis, Modeling and Recognition Systems is to provide a concise and comprehensive coverage of artificial face recognition domain across four major areas of interest:

biometrics, robotics, image databases and cognitive models. Our book aims to provide the reader with current state-of-the-art in these domains. The book is composed of 12 chapters which are grouped in four sections. The chapters in this book describe numerous novel face analysis techniques and approach many unsolved issues. The authors who contributed to this book work as professors and researchers at important institutions across the globe, and are recognized experts in the scientific fields approached here. The topics in this book cover a wide range of issues related to face analysis and here are offered many solutions to open issues. We anticipate that this book will be of special interest to researchers and academics interested in computer vision, biometrics, image processing, pattern recognition and medical diagnosis.

\title{
How to reference
}

In order to correctly reference this scholarly work, feel free to copy and paste the following:

Chloé Wallach and Sadeq Haouzir (2011). Psychiatric Disorders of Face Recognition, Face Analysis, Modeling and Recognition Systems, Dr. Tudor Barbu (Ed.), ISBN: 978-953-307-738-3, InTech, Available from: http://www.intechopen.com/books/face-analysis-modeling-and-recognition-systems/psychiatric-disorders-offace-recognition

\section{INTECH}

open science | open minds

\section{InTech Europe}

University Campus STeP Ri

Slavka Krautzeka 83/A

51000 Rijeka, Croatia

Phone: +385 (51) 770447

Fax: +385 (51) 686166

www.intechopen.com

\section{InTech China}

Unit 405, Office Block, Hotel Equatorial Shanghai

No.65, Yan An Road (West), Shanghai, 200040, China

中国上海市延安西路65号上海国际贵都大饭店办公楼 405 单元

Phone: +86-21-62489820

Fax: $+86-21-62489821$ 
(C) 2011 The Author(s). Licensee IntechOpen. This chapter is distributed under the terms of the Creative Commons Attribution-NonCommercialShareAlike-3.0 License, which permits use, distribution and reproduction for non-commercial purposes, provided the original is properly cited and derivative works building on this content are distributed under the same license. 